\title{
Epidemiological profile of type 1 diabetes among primary school children in Baghdad, Iraq
}

\author{
Sarah Hayder Zalzala, ${ }^{a}$ Faris H. Al-Lami, ${ }^{\text {b Khalid Saeed Fahad }}$
}

\author{
aAl-Karkh Directorate of Health, Ministry of Health, Baghdad, Iraq. \\ ${ }^{\mathrm{b} C}$ Community and Family Medicine Department, College of Medicine, Baghdad University, Baghdad, Iraq. \\ 'Department of Internal Medicine, College of Medicine, Al-Nahrain University, Baghdad, Iraq. \\ Correspondence to: Sarah Hayder Zalzala (email: sarahhaider1988@gmail.com). \\ (Submitted: 23 November 2019 - Revised version received: 02 December 2019 - Accepted: 12 January 2020 - Published online: 26 February 2020)
}

\begin{abstract}
Objectives To estimate the prevalence of type 1 diabetes mellitus in primary school children in Baghdad City, and to evaluate its effect on growth of those children.

Methods This comparative cross-sectional study was conducted in a sample of primary schools in Baghdad city selected by multistage cluster sampling. All primary school students in the selected schools were included. For every diabetic child, we selected a child from the same class who is free from diabetes. Information on disease variables were obtained through sending questionnaire to the children's parents. The Centers for Disease Control and Prevention growth charts were used.

Results The total number of primary school students in the selected 141 schools was 69,115; 110 of them hadT1DM (159/100,000). Female to male ratio was 1.3:1. Obesity and underweight were significantly lower in diabetics than non-diabetic children ( $P=0.03)$.

Conclusion The prevalence of type 1 diabetes mellitus was 159 per 100,000, which was approximate to the prevalence in Saudi Arabia, less than that in Al-Kuwait, but higher than that in Turkey. Percentage of underweight and obesity were lower in the diabetics while overweight percentage was slightly higher compared to the non-diabetics

Keywords type 1 diabetes, primary school children, prevalence, obesity, underweight
\end{abstract}

\section{Introduction}

Type 1 diabetes mellitus (T1DM) is one of the most common chronic diseases of childhood. ${ }^{1}$ Its incidence is rising worldwide, ${ }^{2}$ with reported increases of 2-5 percent per year in the Middle East. ${ }^{3}$ In Iraq, the incidence of T1DM in Basra City is 5-9.99/100,000 per year and was increasing between 2012 and 2016. ${ }^{4}$ Similarly, in Al-Nassiryah City the incidence was also increasing in the last 5 years, ${ }^{5}$ and with the existence of only a few national/regional diabetes registries available to support diabetes research, provide reliable data, and help cope with the widespread threat of this disease, there is a need for establishing a population-based Arab diabetes registry. ${ }^{6}$ Most children with T1DM grow normally, however, poor glycemic control can result in poor linear growth, poor weight gain, and/ or delayed skeletal development. Conversely, treatment with excessive insulin and/or excessive caloric intake can lead to excessive weight gain. And if obesity develops, this can lead to insulin resistance, which complicates diabetes management. ${ }^{\text {? }}$

\section{Purpose of the Study}

To estimate the prevalence of T1DM in primary school children in Baghdad City, and to evaluate its effect on growth of those children.

\section{Material and Methods}

This is a comparative cross-sectional study that was conducted in primary schools in catchment area of 12 primary health care centers (PHCCs) in Al-Karkh side of Baghdad City, selected by multistage cluster sampling (Fig. 1), during the period of Feb 15, 2018-May 1, 2018. The study population included all primary school students in the selected PHCCs (all T1DM students in these schools and an equal number of children

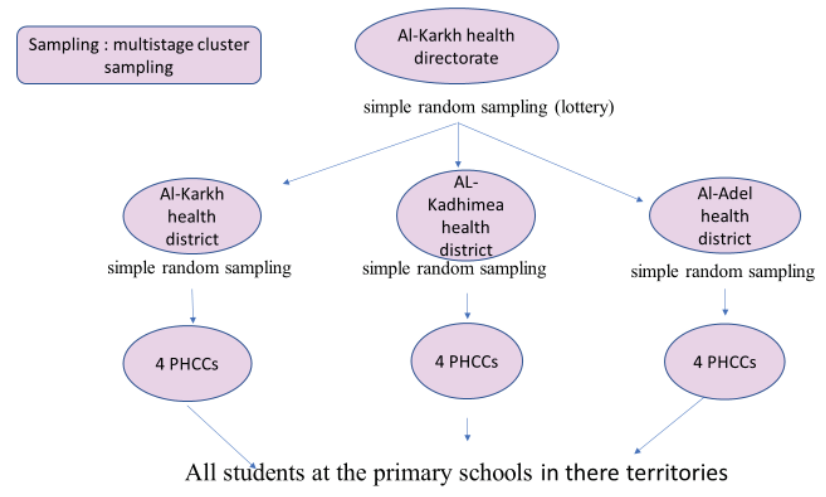

Fig. 1 Multistage cluster sampling.

from the same class and same gender who were T1DMfree were included). Research was done in Al-Karkh side of Baghdad/Iraq in 141 school in the territory of the following PHCCs: Name of PHCCs: Number of schools which covered by local PHCC: (Al Khadhraa PHCC: 8, Al Jamieaa PHCC: 17, The martyr Saif Zakie PHCC: 16, Al Gazalia the first PHCC: 8, Al Dakhilia PHCC: 17, Al Mansoor exemplary PHCC: 14, Martyrs of Alchalijia PHCC: 4, Al Yarmouk PHCC: 13, Al Huriya exemplary PHCC: 12, Al Jawadin exemplary PHCC: 9, Al Zahraa exemplary PHCC: 7, The new Iraq PHCC: 16). School children with any other chronic disease or comorbidities were excluded from the anthropometric measures only.

\section{Data Collection Tools}

Two different types of questionnaires had been used. The first questionnaire was filled by the researcher through direct interview with the primary school teachers. It included questions to gather information on certain student variables, and the anthropometrics' measures; the Centers for Disease Control 
and Prevention (CDC) growth charts were used. ${ }^{8}$ The second questionnaire is translated to Arabic language and was sent to parents of the diabetic group only, to gather information about disease variables: Clinical presentation for DM (classic new onset of chronic polydipsia, polyuria, and weight loss); diabetic ketoacidosis; or asymptomatic incidental discovery, ${ }^{9}$ the duration of DM in year(s), the age at onset of diabetes (early onset diabetes has been variously defined as occurring anywhere from age 4 to age 7 years, ${ }^{10}$ blood glucose monitoring (less than four, four, or more than four times per day) and whether a glucometer in the house was available or not, family history of T1DM, the no. of follow up visit(s) for PHCC, Diabetic center or private doctor in the last 6 months (routine follow-up should be performed at least four times a year, ${ }^{11}$ number of ER visits and hospital admission in the last 6 months, and the value of the last HbA1C test for each child were all inquired. The statistical software (Statistical Package for the Social Science, release 11.0 for Windows; SPSS; Chicago, IL) was used for data entry and analysis. Descriptive statistics were used to summarize subject characteristics and questionnaire results. Chi-square test of independence was used to test qualitative and frequency data. P-value of $<0.05$ was considered significant. A written informed consent was obtained from parents of each enrolled student. All personal information was kept anonymous. Administrative approval was granted from research committee in Ministry of Health, Iraq.

\section{Result}

The total number of primary school students in the selected 141 schools was 69,$115 ; 110$ of them had T1DM. The highest prevalence of diabetes was in $\mathrm{Al}$ Mansoor exemplary PHCC (338 per 100,000) while the overall prevalence of diabetes was 159 per 100,000 . The proportion of female was slightly more than male with female to male ratio of 1.3:1, diabetics' age ranged 6-14 years old. The distribution of the diabetics according to age, sex, and disease variables is shown in Table 1. The distribution of the study group according to anthropometric measures is shown in Table 2.

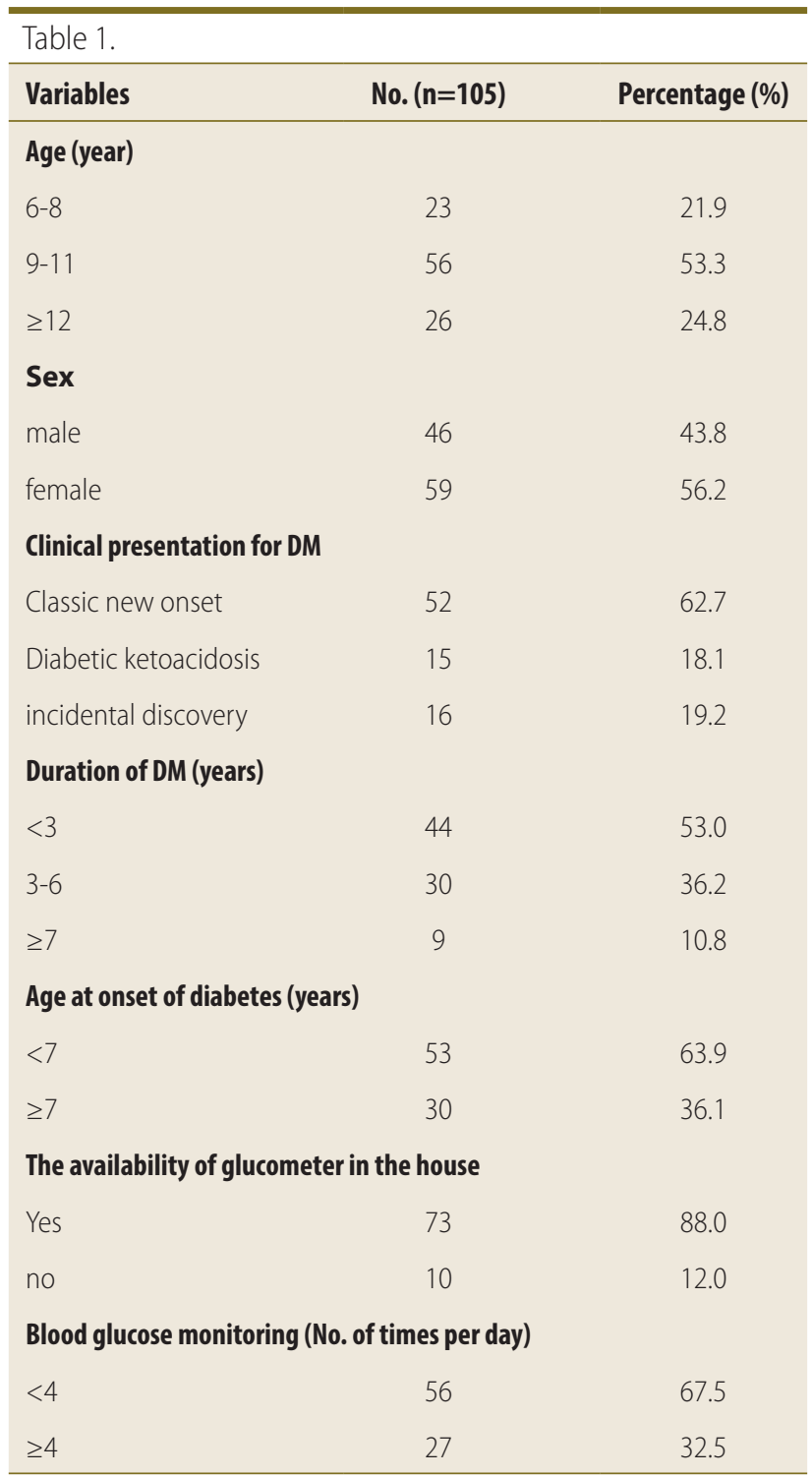

\begin{tabular}{|c|c|c|c|c|c|c|}
\hline \multirow{2}{*}{$\begin{array}{l}\text { Variable } \\
\text { BMI percentile }\end{array}$} & \multicolumn{2}{|c|}{ Diabetics } & \multicolumn{2}{|c|}{ Nondiabetics } & \multirow{2}{*}{ Chi square } & \multirow{2}{*}{ P value } \\
\hline & No. $(n=102)$ & Percentage (\%) & No. $(n=105)$ & Percentage (\%) & & \\
\hline$<5$ & 2 & 2.0 & 9 & 8.6 & \multirow{4}{*}{8.929} & \multirow{4}{*}{0.030} \\
\hline$\geq 5$ and $<85$ & 76 & 74.5 & 66 & 62.9 & & \\
\hline$\geq 85$ and $<95$ & 17 & 16.6 & 14 & 13.3 & & \\
\hline$\geq 95$ & 7 & 6.9 & 16 & 15.2 & & \\
\hline \multicolumn{7}{|c|}{ Weight for age percentile } \\
\hline$<5$ & 5 & 4.9 & 2 & 1.9 & & \\
\hline$\geq 5$ and $\leq 95$ & 91 & 89.2 & 91 & 86.7 & 3.243 & 0.198 \\
\hline$>95$ & 6 & 5.9 & 12 & 11.4 & & \\
\hline \multicolumn{7}{|c|}{ Height for age (percentile) } \\
\hline$<5$ & 10 & 9.8 & 2 & 1.9 & & \\
\hline$\geq 5$ and $\leq 95$ & 89 & 87.2 & 100 & 95.2 & 5.931 & 0.052 \\
\hline$>95$ & 3 & 3.0 & 3 & 2.9 & & \\
\hline
\end{tabular}


The majority of patients (62.7\%) were diagnosed by classic symptoms of diabetes. The mean for duration of DM was $3.9 \pm 2.4$ (SD) years and $63.9 \%$ have DM before the age of 7 years. Around $10 \%$ of children didn't have follow-up visit at all, $50 \%$ of them had at least one hospital admission and frequent attacks of hypoglycemia in the last 6 months. Only 1 of them had documented HbAlc value which was $13 \%$. Among the reminder $90 \%$ whom had gone for follow-up visit, $14.5 \%$ had 1 visit, $13.3 \%$ had 2 visits and $62.6 \%$ had $>2$ visits per 6 months. According to where they went for follow-up, $75.9 \%$ visited a private doctor and only $54.2 \%$ of children had documented $\mathrm{HbA} 1 \mathrm{c}$ result.

\section{Discussion}

The prevalence of T1DM has been reported to vary greatly among different countries, within countries, and among different ethnic populations. ${ }^{12}$ Recently, a study reported that the prevalence and incidence of T1DM were found to be variable among the Arabs. ${ }^{6}$ This study showed that prevalence of diabetes in primary school children in Baghdad was 159 per 100,000, which was higher than Basrah where prevalence rate was 87 per $100,000,{ }^{4}$ despite the age group sample was much wider than this study (all $\leq 40$ years old), but these findings were based on a retrospective data analysis of electronic archives for patients with T1DM registered in Faiha Specialized Diabetes, Endocrine, and Metabolism Center, which is a tertiary referring Center in Basrah. The prevalence of T1DM was 269.9 per 100,000 among 6-18-year-old Kuwaiti children, ${ }^{13}$ while it was 109 per 100,000 in Saudi Arabian children (7-12 years old $)^{14}$ which is approximate to our results. Lower prevalence found in children who lived in the Nile Delta region of Egypt $(26.8 \text { per 100,000 })^{15}$ and school children living in Istanbul, Turkey, (67 per 100,000). ${ }^{16}$ These variations might be due to the variation in the incidence of T1DM as it varied based upon geography, age, gender, family history, and ethnicity. ${ }^{7}$ When people relocate from a region of low to high incidence, their risk of developing T1DM also increases, suggesting a causative role for environmental factor(s). However, wide variations in incidence occur between neighboring areas of similar latitude, suggesting the presence of other contributing risk factors and demonstrating the complexity of the pathogenesis of T1DM. ${ }^{7}$ A study found that there is considerable variation among Arab countries, which could not be explained on genetic or climatic variations alone, other environmental factors particularly nutritional ones including high intake of dairy products and vitamin D deficiency are possibly operating. ${ }^{17}$ The proportion of female was slightly more than male, which agreed with two studies as prevalence for T1DM slightly favors females in Australia, ${ }^{18}$ and Japan, ${ }^{19}$ but disagree with another study which slightly favors males in the USA, ${ }^{20}$ and it was near parity in North-West England. ${ }^{21}$ The lifetime risk of developing T1DM is significantly increased in close relatives of a patient with T1DM..$^{22}$ In this study, around $30.1 \%$ of diabetics had family history of T1DM (aunts and uncles were included), as they found that $10 \%-20 \%$ of newly diagnosed childhood cases of T1DM have an affected first-degree relative, ${ }^{2}$ and familial history was more than $20 \%$ when accounting for the extended family history. ${ }^{23}$ The higher percentage of underweight in the non-diabetics group might be due to the primary cause of poor weight gain in school-aged children and adolescents which is inadequate dietary intake relative to typical metabolic and growth needs. ${ }^{24}$ Children may ingest too much juice or other non-nutritious liquid, resulting in satiation and decreased appetite for higher caloric density or more nutritious solid foods ${ }^{25,26}$ while these beverages might be more restricted in the diabetics, and these results is approximate to Turkish study as they found that rates of overweight and obesity were $21.2 \%$ and $14.6 \%$ (35.8\% combined), using the WHO growth curve, ${ }^{27}$ compared to $13.3 \%$ and $15.2 \%(28.5 \%$ combined) in this study. About $2 \%$ of diabetics were underweight, $74 \%$ normal, $16.6 \%$ overweight and $6.9 \%$ obese, which agreed with a Canadian study as they found that Children with T1DM are more overweight, but not more obese. ${ }^{28}$ An Australasian study showed that the prevalence of being overweight was $19 \%$ and of obesity was $6 \%,{ }^{29}$ and another study where none of the study subjects were underweight, $69 \%$ were within the normal weight range. ${ }^{30}$ The challenges for maintaining healthy weight associated with T1DM include weight gain as the result of supra-physiological insulin doses, and overeating to avoid or treat hypoglycemia. ${ }^{29}$ Another study showed that pre- and post-onset body mass index in children with T1DM were both well above the population mean, were closely correlated with each other and (inversely) with age at onset. ${ }^{31}$ Proper attention to diet is a major factor in minimizing hypoglycemia and weight gain while achieving glycemic control. ${ }^{32}$ The majority of patients were diagnosed by classic symptoms of diabetes which agreed with another Iraqi study. ${ }^{33}$ Although routine follow-up should be performed at least four times a year, ${ }^{11}$ about $10 \%$ of parents didn't go for follow-up visit at all, 50\% of those had at least one hospital admission and frequent attacks of hypoglycemia in the last 6 months and only 1 of them had documented HbAlc value which was $13 \%$. Cardwell et al found that patients attending less than four diabetes clinics in the last year had a significantly higher HbAlc level compared to those attending exactly four clinics level. ${ }^{34}$

\section{Acknowledgments}

Authors would like to express deepest thanks for all the staff in the selected Primary Health Care Centers and Primary Schools for their generous help and support during the time of this project, especially to:

Dr. Zainab, Al Dakhilia PHCC.

Mrs. Shatha, Al Jawadin exemplary PHCC.

I would like to apologize gratefully to all those people who helped me to complete my work without being able to mention them by names.

\section{Conflicts of Interest Disclosure:}

None

\section{References}

1. Levitsky LL, Misra M, Wolfsdorf J, Hoppin A. Management of type 1 diabetes mellitus in children and adolescents. Complications and screening in children and adolescents with type. 2011;1.

2. Tuomilehto J. The emerging global epidemic of type 1 diabetes. Curr. Diab. Rep. 2013;13(6):795-804 
3. Mamoulakis D, Galanakis E, Bicouvarakis S, Paraskakis E, Sbyrakis S. Epidemiology of childhood type I diabetes in Crete, 1990-2001. Acta Paediatr. 2003;92(6):737-9

4. Almahfoodh D, Alabbood M, Alali A, Mansour A. Epidemiology of type 1 diabetes mellitus in Basrah, Southern Iraq: A retrospective study. Diab. Res. Clin. Pract. 2017;133:104-8.

5. AL-Rubaee RJ. Newly diagnosed type 1 Diabetes Mellitus in Dhi-qar city (IRAQ) sociodemographic study.

6. Zayed H, Ouhtit A, El Bekay R. An Arab registry for type 1 diabetes: global benefits for type 1 diabetes patients. Curr. Med. Res. Opin. 2016;32(10):1681-

7. Levitsky LL, Misra M, Wolfsdorf J, Hoppin A. Complications and screening in children and adolescents with type 1 diabetes mellitus. Up To Date. 2007;17(1).

8. Phillips SM, Shulman RJ, Motil K. Measurement of growth in children. UpToDate, Basow, DS (ed), UpToDate, Waltham, MA. 2011.

9. Levitsky LL, Misra M. Epidemiology, presentation, and diagnosis of type 1 diabetes mellitus in children and adolescents. UpToDate Waltham, MA: UpToDate. 2007

10. Ack M, Miller I, Weil WB. Intelligence of children with diabetes mellitus. Pediatrics. 1961;28(5):764-70.

11. Chiang JL, Kirkman MS, Laffel LM, Peters AL. Type 1 diabetes through the life span: a position statement of the American Diabetes Association. Diab. Care. 2014;37(7):2034-54

12. Dabelea D. The accelerating epidemic of childhood diabetes. Lancet. 2009;373(9680):1999-2000.

13. Moussa MA, Alsaeid M, Abdella N, Refai TM, Al-Sheikh N, Gomez JE. Prevalence of type 1 diabetes among 6-to 18-year-old Kuwaiti children. Med. Princip. Pract. 2005;14(2):87-91.

14. Al-Herbish AS, El-Mouzan MI, Al-Salloum AA, Al-Qurachi MM, Al-Omar AA. Prevalence of type 1 diabetes mellitus in Saudi Arabian children and adolescents. Saudi Med. J. 2008;29(9):1285-8.

15. El-Ziny MAE-M, Salem NA-B, El-Hawary AK, Chalaby NM, Elsharkawy AA-E. Epidemiology of childhood type 1 diabetes mellitus in Nile Delta, northern Egypt-a retrospective study. J. Clin. Res. Pediatr. Endocrinol. 2014;6(1):9.

16. Akesen E, Turan S, Güran T, Atay Z, Save D, Bereket A. Prevalence of type 1 diabetes mellitus in 6-18-yr-old school children living in Istanbul, Turkey. Pediatr. Diab. 2011;12(6):567-71.

17. Abdullah MA. Epidemiology of type I diabetes mellitus among Arab children. Saudi Med. J. 2005;26(6):911-7.

18. Speight J, Browne JL, Holmes-Truscott E, Hendrieckx C, Pouwer F. Diabetes MILES-Australia (Management and Impact for Long-term Empowerment and Success): methods and sample characteristics of a national survey of the psychological aspects of living with type 1 or type 2 diabetes in Australian adults. BMC Public Health. 2012;12(1):120.
19. Kawasaki E, Eguchi K. Is type 1 diabetes in the Japanese population the same as among Caucasians? Ann. NY Acad. Sci. 2004;1037(1):96-103.

20. Menke A, Orchard TJ, Imperatore G, Bullard KM, Mayer-Davis E, Cowie CC. The prevalence of type 1 diabetes in the United States. Epidemiology (Cambridge, Mass). 2013;24(5):773.

21. Anderson SG, Narayanan RP, Amlesh J, Qureshi MZ, Heald AH. Type 1 diabetes in Cheshire: cardiometabolic risk factor trends (2004-2009). Prim. Care Diab. 2012;6(2):123-6.

22. Mayer-Davis EJ, Kahkoska AR, Jefferies C, Dabelea D, Balde N, Gong CX, et al. ISPAD Clinical Practice Consensus Guidelines 2018: Definition, epidemiology, and classification of diabetes in children and adolescents. Pediatr. Diab. 2018;19:7-19.

23. Parkkola A, Härkönen T, Ryhänen SJ, Ilonen J, Knip M, Register FPD. Extended family history of type 1 diabetes and phenotype and genotype of newly diagnosed children. Diab. Care. 2013;36(2):348-54

24. Gahagan S. Failure to Thrive: A Consequence of. Pediatrics in Review. 2006;27(1):e1-e11.

25. Munoz KA, Krebs-Smith SM, Ballard-Barbash R, Cleveland LE. Food intakes of US children and adolescents compared with recommendations. Pediatrics. 1997:100(3):323-9.

26. Kant AK. Reported consumption of low-nutrient-density foods by American children and adolescents: nutritional and health correlates, NHANES III, 1988 to 1994. Arch. Pediatr. Adolesc. Med. 2003;157(8):789-96.

27. Yardim MS, Ozcebe H, Araz OM, Uner S, Li S, Unlu H, et al. Prevalence of childhood obesity and related parental factors in Ankara, Turkey. 2018.

28. Sandhu N, Witmans MB, Lemay J-F, Crawford S, Jadavji N, Pacaud D. Prevalence of overweight and obesity in children and adolescents with type 1 diabetes mellitus. J. Pediatr. Endocrinol. Metab. 2008;21(7):631-40.

29. Phelan H, Clapin H, Bruns L, Cameron FJ, Cotterill AM, Couper JJ, et al. The Australasian Diabetes Data Network: first national audit of children and adolescents with type 1 diabetes. Med. J. Austr. 2017;206(3):121-5.

30. Daneman D. Assessment of intakes of artificial sweeteners in children with type 1 diabetes mellitus. Can. J. Diab. 2004;28(2):00-

31. Betts P, Mulligan J, Ward P, Smith B, Wilkin T. Increasing body weight predicts the earlier onset of insulin-dependant diabetes in childhood: Testing the 'accelerator hypothesis'(2). Diab. Med. 2005;22(2):144-51.

32. Delahanty LM, Halford BN. The role of diet behaviors in achieving improved glycemic control in intensively treated patients in the Diabetes Control and Complications Trial. Diab. Care. 1993;16(11):1453-8.

33. Abd-Alrazak OM, Ghalib BA, Abduljabbar HA. Growth Indices among Children and Adolescents with Type 1 Diabetes-Baghdad-Iraq, 2013. J. Facult. Med. 2014;56(3):258-63

34. Cardwell C, Patterson C, Allen M, Carson D. Diabetes care provision and glycaemic control in Northern Ireland: a UK regional audit. Arch Dis. Childhood. 2005:90(5):468-73.

This work is licensed under a Creative Commons Attribution-NonCommercial 3.0 Unported License which allows users to read, copy, distribute and make derivative works for non-commercial purposes from the material, as long as the author of the original work is cited properly. 